\title{
Different Leishmania species determine distinct profiles of immune and histopathological responses in CBA mice
}

\author{
Valderes Lemos de Souza, Juliana Ascenção Souza, Tânia Maria Correia Silva, Patrícia Sampaio Tavares Veras, \\ Luiz Antônio Rodrigues de-Freitas* \\ LPBC, Laboratory of Pathology and Cellular Biology, Gonçalo Moniz Research Center, Oswaldo Cruz Foundation (FIOCRUZ), 121, \\ $R$ Valdemar Falcão, Brotas, Salvador, Babia 40295-001, Brazil
}

(Received 16 June 2000; accepted 13 September 2000)

\begin{abstract}
Most experimental studies on leishmaniasis compare two different inbred strains of mice that are resistant or susceptible to one species of Leishmania. In the present study we characterized some cytokines and nitric oxide production as well as histological changes related to resistance and susceptibility in isogenic CBA mice infected with Leishmania major or Leishmania amazonensis. CBA mice are capable of controlling infection with $L$. major, but they succumb to infection with $L$. amazonensis. Cells from susceptible $L$. amazonensis-infected CBA mice produced interleukin (IL)- 4 and IL-10 but no interferon (IFN)- $\gamma$. On the other hand, resistant L. major-infected CBA mice produced IFN- $\gamma$ and IL-10, but IL- 4 was detected only in the first week of infection. Histopathological studies showed patterns of tissue responses at the site of the infection and in the draining lymph nodes that correlated with resistance or susceptibility. Resistant mice showed a mixed inflammatory cell infiltration and granulomas in the lesions, whereas in susceptible mice only heavily parasitized macrophages were seen. Our results indicate an important role of the parasite species in determining the pattern of immune response. L. amazonensis induces a Th2-type immune response, whereas $L$. major induces a Th1-type response. These factors must be identified and taken into account in the strategies for the development of vaccines against leishmaniasis. The model presented here will be useful for the study of such factors. () 2000 Éditions scientifiques et médicales Elsevier SAS
\end{abstract}

CBA / leishmaniasis / histopathology / immunology / Leishmania amazonensis / Leishmania major

\section{Introduction}

Leishmaniasis is an endemic disease in several parts of the world. A broad spectrum of clinical manifestations, ranging from asymptomatic to cutaneous, mucocutaneous and visceral leishmaniasis, is recognized. Different species of Leishmania cause disease in different areas of the world. Cutaneous leishmaniasis may be caused by Leishmania major in Asia and by L. amazonensis or L. braziliensis in South America, including Brazil [1,2]. The clinical manifestations of the disease depend on the species of the parasite and the immune response of the host to the infecting agent. In both human and murine leishmaniasis,

* Correspondence and reprints.

E-mail address: 1freitas@svn.com.br (L.A. Rodrigues de-Freitas). resistance and recovery depend on the capacity of the host to mount an adequate cell-mediated immune response [3-6].

Studies have shown that the main factor controlling murine leishmaniasis is the type of the $\mathrm{CD}^{+} \mathrm{T}$-cell response. Cells from resistant mice produce interferon (IFN)- $\gamma$ but little or no interleukin (IL)- 4 when stimulated in vitro, whereas cells from susceptible mice produce IL-4 and no IFN $-\gamma$. Thus, protection is related to the Th1-type of the cellular immune response, while susceptibility is related to the Th2-type of response [7-10].

The Th1 1 Th2 paradigm in leishmaniasis has been largely established by comparing strains of mice susceptible to $L$. major infection with resistant mouse strains. $\mathrm{BALB} / \mathrm{C}$ mice have been used as the prototype to study mechanisms involved in susceptibility to $L$. major, whereas resistance has been studied in C57BL/ 6 mice $[7,8,11]$. It 
is possible, however, that the mechanisms underlying resistance and susceptibility could be different from those described for $\mathrm{BALB} / \mathrm{C}$ and $\mathrm{C} 57 \mathrm{BL} / 6$ mice infected with L. major if different strains of mice and different species of parasite are used.

Few studies have been carried out to investigate the host response to infection with species of Leishmania that cause disease in the New World. All strains of mice appear to be resistant to L. braziliensis; thus, a good murine model of infection with this species of parasite is not available [12-15]. In contrast, most strains of mice are susceptible to infection with Leishmania from the mexicana complex $[13,16-19]$. Afonso et al. [17] showed that the susceptibility of C57BL/10 mice to L. amazonensis was related to the absence of a Th1 immune response but not controlled exclusively by Th2 cells. Similar results were described by Soong et al. [19] using C57BL/6 mice infected with L. amazonensis. Their results are different from those obtained with BALB/c mice, in which susceptibility is clearly related to Th2 response $[7,8]$.

Inbred CBA mice are resistant to infection with $L$. major [20] but are susceptible to infection with $L$. amazonensis [21]. The mechanisms underlying the susceptibility of CBA mice to infection with $L$. amazonensis have not yet been described. In the present study we have characterized some cytokines and nitric oxide $(\mathrm{NO})$ production and performed histopathological studies of the lesions and of the draining lymph node to correlate morphological findings with immunological patterns related to resistance or susceptibility.

\section{Materials and methods}

\subsection{Animals}

Inbred 6-8-week-old CBA and BALB/C mice were obtained from the Animal Facilities Center of FIOCRUZ (Rio de Janeiro, Brazil) and maintained in animal facilities at Gonçalo Moniz Research Center in Salvador, State of Bahia.

\subsection{Parasites}

L. amazonensis (MHOM/Br88/Ba-125 isolate) and L. major (MHOM/IR/-173) were maintained by periodic passages in BALB/c mice. Promastigotes were grown in axenic liver infusion trypsin medium supplemented with $10 \%$ fetal bovine serum (FBS) (Hyclone, Logan, Utah) [22]. Stationary-phase promastigotes were used to infect mice.

\subsection{Infection and measurement of cutaneous lesions}

Infection with L. major or L. amazonensis was accomplished by injecting $5 \times 10^{6}$ promastigotes in $25 \mu \mathrm{L}$ subcutaneously into the left hind footpad of CBA and BALB/c mice. Footpad thickness was measured periodically over 10 weeks with a vernier caliper (Mitutoyo, São Paulo, SP). Differences between the infected footpad and the contralateral uninfected one were expressed as 'lesion size' in millimeters.

Because BALB/c mice are susceptible to both $L$. major and $L$. amazonensis, for each experiment they were inocu- lated with both species of Leishmania as positive control of the infection.

\subsection{Parasite quantification}

Enumeration of viable parasites in the infected footpad was performed using a limiting dilution assay as previously described [17]. Results were expressed as -log of parasite titer.

\subsection{Histological study}

In order to study tissue response to the infection at 3, 7, 21,42 and 70 days after infection, three mice from each group were killed. Infected footpads and popliteal draining lymph nodes were removed and immediately placed in $10 \%$ formaldehyde. After $12-24 \mathrm{~h}$ of fixation, bones were decalcified in $7 \%$ nitric acid. Tissues were embedded in paraffin, and sections $3-5 \mu \mathrm{m}$ thick were stained with hematoxilin and eosin $(\mathrm{H} \& \mathrm{E})$.

\subsection{Immunohistochemical staining}

To demonstrate the presence of parasites in the site of infection and in the draining lymph nodes, immunostaining for Leishmania was performed in 3-5- $\mu$ m-thick sections obtained from formalin-fixed and paraffin-embedded tissue. The indirect immunoperoxidase technique was applied using a rabbit polyclonal antibody against Leishmania [23]. The antibody was diluted 1:1500 in PBS containing $10 \%$ normal mouse serum. For negative control, non-related rabbit IgG replaced the specific antibody.

\subsection{Cell culture and in vitro stimulation}

Popliteal lymph nodes were aseptically removed 7, 49 and 70 days after infection, and pooled cell suspensions were prepared for each time point. Cells were washed and resuspended at $3 \times 10^{6}$ cells $/ \mathrm{mL}$ in culture medium consisting of Dulbecco's modified Eagle's medium supplemented with $0.5 \%$ FBS, 2 mM L-glutamine, $100 \mathrm{U} / 100$ $\mu \mathrm{g} / \mathrm{mL}$ of penicillin/streptomycin, $25 \mathrm{mM}$ HEPES, $3.7 \mathrm{~g} / \mathrm{L}$ sodium bicarbonate (Sigma, St. Louis, MO), $25.4 \mathrm{mM}$ sodium pyruvate (GIBCO, Grand Island, NY), $1.6 \mathrm{mM}$ L-arginine hydrocloride (Sigma) and $5 \times 10^{-5} \mathrm{M} \beta$-2mercaptoethanol (GIBCO). In order to assay for cytokine production, $3 \times 10^{6}$ cells $/ \mathrm{mL}$ were plated on 24-well tissue culture plates (Costar 3524, Cambridge, MA). L. major or L. amazonensis at $3 \times 10^{5}$ promastigotes $/ \mathrm{mL}$ were added to each well; control cultures contained either no parasites or $10 \mu \mathrm{g} / \mathrm{mL}$ of concanavalin A (positive control). Supernatants of the cultures were collected at $72 \mathrm{~h}$ and maintained at $-20{ }^{\circ} \mathrm{C}$ until tested for the presence of IFN- $\gamma$, IL-4, IL-10 and NO.

\subsection{Cytokine production}

IFN- $\gamma$, IL-4 and IL-10 were measured by sandwich ELISA according to standard procedures [24]. IFN- $\gamma$, IL-4 and IL-10 levels were determined using, respectively, $2 \mu$ g, $1 \mu \mathrm{g}$ and $2 \mu \mathrm{g}$ per $\mathrm{mL}$ of capture mAbs R4-642 (anti-mouse IFN- $\gamma$ ), 11B11 (anti-mouse IL-4) and JES5-2A5 (anti-mouse $\mathrm{IL}-10)$ as the primary antibody and $2 \mu \mathrm{g}$ per $\mathrm{mL}$ of biotinlabeled mAbs XMG1.2 (anti-mouse IFN- $\gamma$ ), BVD6-24G2 (anti-mouse IL-4) and SXC-1 (anti-IL-10). All the reagents used including the recombinant mouse IFN- $\gamma, \mathrm{IL}-4$ and 


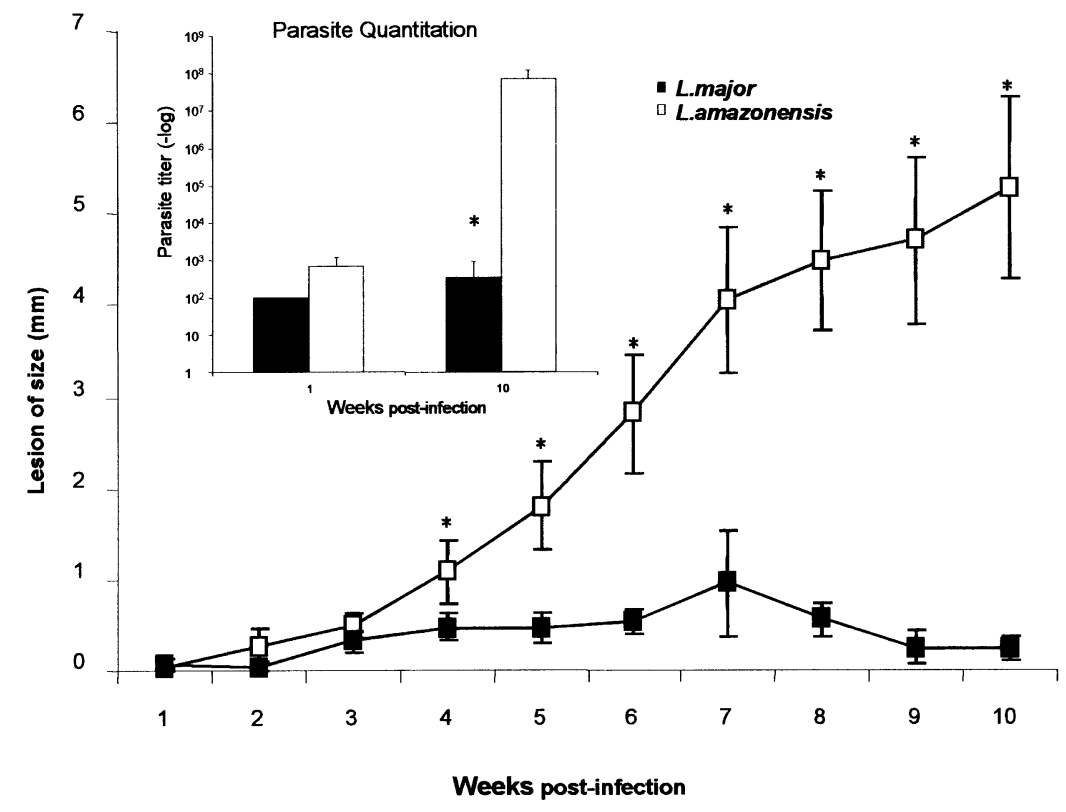

Figure 1. Course of L. amazonensis or L. major infection in CBA mice. Lesion size (expressed in $\mathrm{mm}$ ) represents the mean difference \pm SD between infected and uninfected hind footpads for ten mice. Insert: parasite burden in footpad lesions was assessed using a limiting dilution assay. Three mice in each group were tested and results are expressed as $-\log$ of the dilution. Asterisks indicate statistically significant differences between the groups $(P<0.05)$. The results shown are representative of three experiments.
IL-10 standards were purchased from Pharmingen, San Diego, CA. The standard curves used express the results in nanograms and picograms per milliliter.

\section{9. $\mathrm{NO}_{2}$ release}

Supernatants obtained from lymph node cell (LNC) cultures of infected mice as described above were assayed for the ability to release $\mathrm{NO}_{2}$ by the Griess reaction [25].

\subsection{Statistical analysis}

ANOVA and the Newman-Keuls test were used to compare lesion size. The Mann-Whitney test was used to compare the parasite burden in different groups of mice. An unpaired Student's t-test was performed to compare cytokine production. Differences were considered significant when $P<0.05$.

\section{Results}

\subsection{Course of $L$. major and $L$. amazonensis in CBA mice}

As shown in figure 1, a sharp difference in the course of the infection was observed in L. amazonensis-infected CBA mice compared with that of L. major-infected ones. Mice infected with $L$. amazonensis developed progressive lesions that showed necrosis and ulceration at 9 weeks after infection. However, in CBA mice infected with L. major, lesions augmented from the 2 nd to the 7 th week after infection and then decreased progressively to a cure at 10 weeks post-infection. At the same time, BALB/c mice infected with either L. amazonensis or L. major showed uncontrolled progressive lesions (data not shown).

Figure 1 (insert) shows that the difference in the outcome of the infection was not due to differences in the number of parasites in the inoculum. The parasite burden in the footpad of mice infected with either $L$. amazonensis or L. major was similar in the first week after infection $(P=$ $0.4)$ and became clearly different by the end of the experiment $(P<0.001)$.

\subsection{Cytokine profile in CBA mice infected with either $L$. major or $L$. amazonensis}

The cytokines produced by LNCs draining the lesions of L. major-infected mice and $L$. amazonensis-infected mice were measured to determine whether resistance and susceptibility were related to the development of CD4 ${ }^{+} \mathrm{Th} 1-$ and Th2-type responses, respectively $[7,8,10,11]$. IFN- $\gamma$ was assessed as a marker of a Th1-type immune response, whereas IL-4 was assessed as a marker of the Th2-type immune response.

Cells from $L$. major-infected CBA mice produced higher amounts of IFN- $\gamma$ at all time points (figure $2 A$ ). At 7 and 49 days after infection L. major-infected mice produced approximately 23-fold more IFN- $\gamma$ than L. amazonensisinfected ones. By the end of the experiments, IFN- $\gamma$ was detected only in mice infected with L. major.

At 1 week post-infection, LNCs from resistant $L$. majorinfected CBA mice produced about three-fold more IL-4 than cells from susceptible $L$. amazonensis-infected mice (figure 2B). However, at 7 weeks post-infection, IL-4 production by cells from susceptible $L$. amazonensis-infected mice was five-fold higher than that by cells of L. majorinfected mice. At 10 weeks post-infection, IL-4 was only detected in supernatants of cells obtained from L. amazonensis-infected mice. By this time point, L. amazonensis-infected mice had progressive uncontrolled lesions, whereas L. major-infected ones had controlled the infection.

IL-10 is a cytokine that has been considered to inhibit the Th1 response, thus favoring a Th2 response [26]. However, at 7 days post-infection, the production of IL-10 was significantly higher by the cells from L. major-infected mice than by those of L. amazonensis-infected ones 

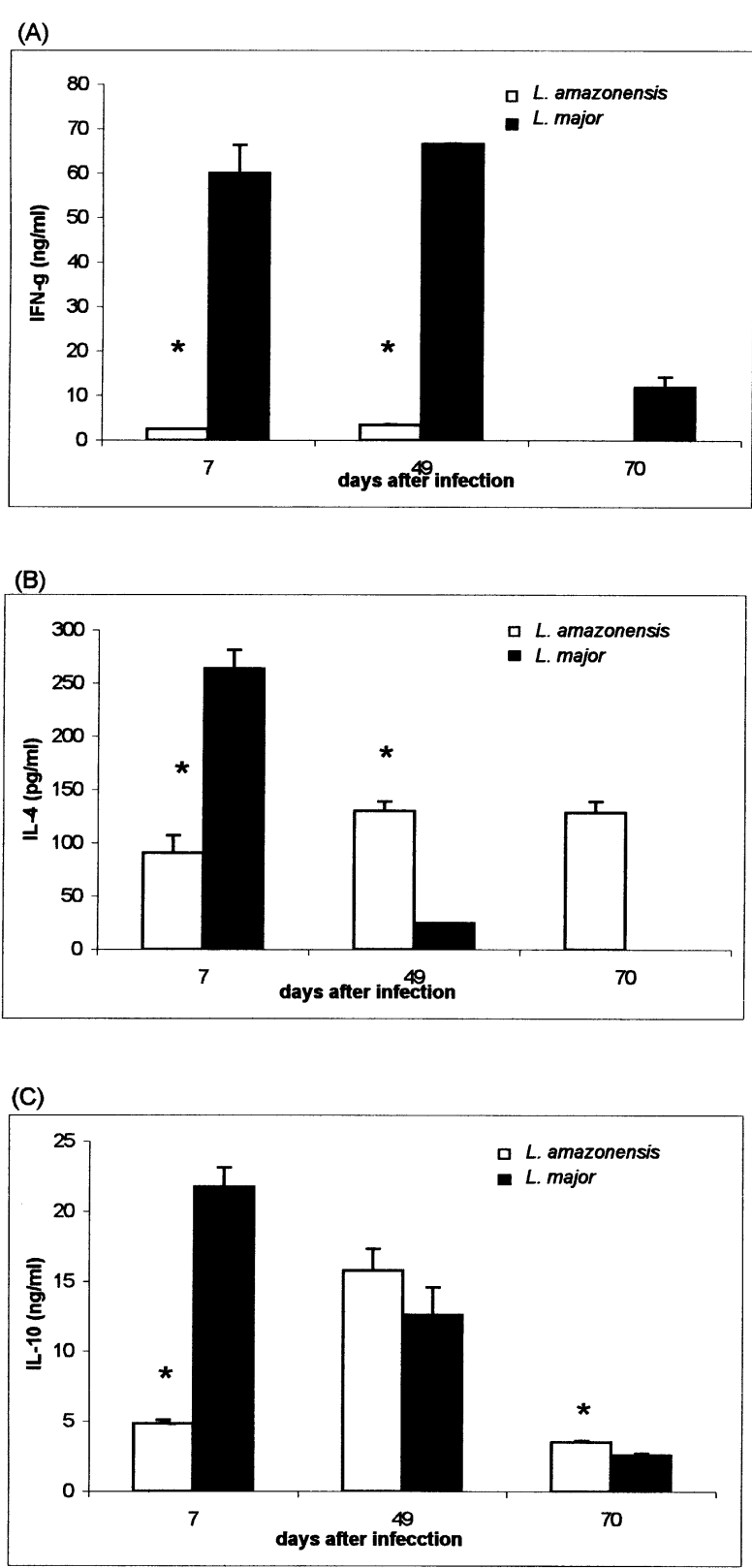

Figure 2. a) IFN- $\gamma$, b) IL-4 and c) IL-10 production by LNCs from CBA mice infected with L. amazonensis or L. major. Cytokines were determined 7,49 , and 70 days after infection by in vitro stimulation of popliteal lymph node cells after $72 \mathrm{~h}$ of stimulation with live promastigotes of $L$. amazonensis or $L$. major as described in Materials and methods. LNCs from both groups of mice produced high levels of IFN- $\gamma$, IL- 4 and IL-10 upon stimulation with concavalin A. Culture supernatants of non-stimulated cells were below the detection limit of the assays. Each bar represents the mean value \pm SD of five mice, from one of three representative experiments. Asterisks indicate statistically significant differences between the groups $(P \leq 0.05)$.

$(P<0.001)$. At 49 days post-infection, no difference in the production of IL-10 was detected (figure 2C). By the end of the experiments the levels of IL-10 were very low in both groups of mice.

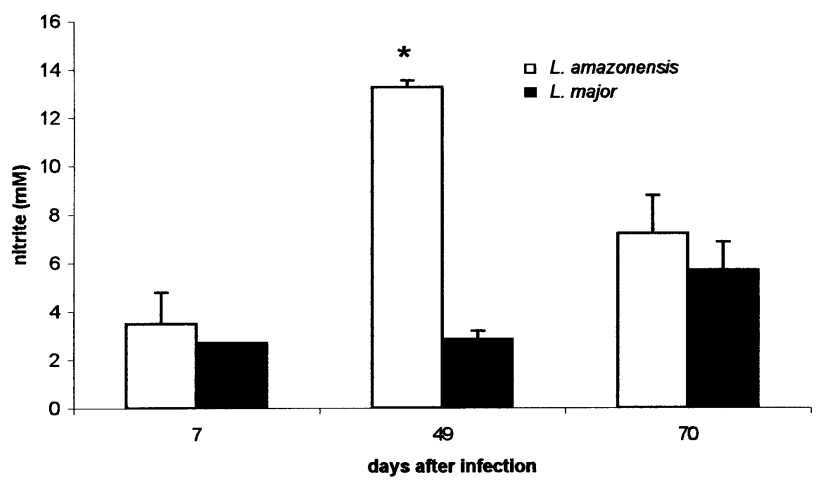

Figure 3. NO production by LNCs from CBA mice infected with $L$. amazonensis or L. major. The Griess reaction was used to measure the accumulation of $\mathrm{NO}_{2}{ }^{-}$in the culture supernatants of popliteal lymph node cells after $72 \mathrm{~h}$ of stimulation with live promastigotes of L. amazonensis or L. major. Each bar represents the mean $\pm \mathrm{SD}$ of five mice, from one of three representative experiments. Asterisks indicate a statistically significant difference between the groups $(P \leq 0.05)$.

\subsection{NO production}

Both L. major- and L. amazonensis-infected CBA mice produced similar amounts of $\mathrm{NO}$ at 7 and 70 days postinfection (figure 3). At 49 days post-infection, the amount of $\mathrm{NO}$ produced by $L$. amazonensis-infected mice was five-fold higher than that produced by L. major-infected mice $(P=0.0001)$. However, this higher amount of $\mathrm{NO}$ did not correlate with resistance to $L$. amazonensis.

\subsection{Histopathological studies}

The lesions observed in the footpads of L. major- and L. amazonensis-infected mice 3 days after inoculation were alike. They were represented by an acute inflammatory response with moderate infiltration of granulocytes and macrophages, which were located at the dermis. Macrophages and a few granulocytes were parasitized by amastigote forms of leishmania (data not shown).

A clear-cut difference appeared in the lesions after 14 days of inoculation. Changes in the L. major-infected mice were represented by a diffuse and mixed-cell inflammatory reaction (figure $4 A$ ). Parasitized macrophages were seen among many small lymphocytes and few plasma cells and granulocytes (figure 4C). As infection progressed, the number of lymphocytes increased in the lesions, whereas the number of parasitized macrophages decreased. Many epithelioid macrophages and few granulomas were observed; areas of focal fibrinoid necrosis were seen. At 70 days post-infection, the inflammatory infiltration was scarce. Fibroblast proliferation and collagen formation appeared throughout the lesion, giving rise to a more or less dense stroma (figure $4 E$ ).

In the $L$. amazonensis-infected mice the lesions were represented by an extensive collection of vacuolated and heavily parasitized macrophages (figure $4 B$ ). Amastigote forms of leishmania were seen attached to the wall of the parasitophorous vacuoles (figure $4 D$ ). The number of para- 


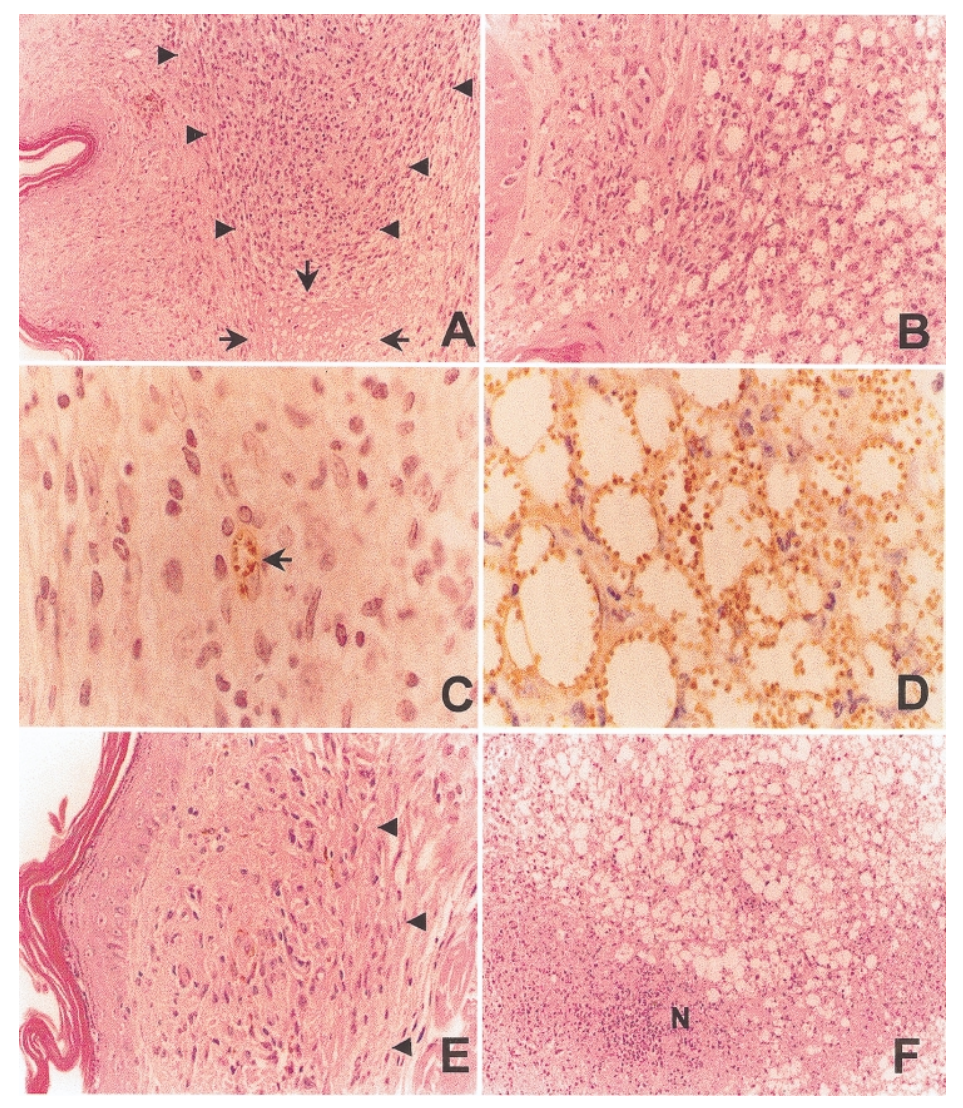

Figure 4. Histological changes in the site of inoculation of L. major or L. amazonensis. A) A mixed inflammatory cell infiltration composed of many macrophages and lymphocytes forming a granuloma in $L$. major-infected CBA mouse (arrowheads). Fibrinoid necrosis is present (arrows) (H \& E, original magnification $\times 70) 42$ days after infection. B) Most cells seen in the inflammatory infiltrate of L. amazonensisinfected mice are parasitized macrophages that show large parasitophorous vacuoles containing many amastigote parasites ( $\mathrm{H} \& \mathrm{E}$, original magnification $\times 140) 42$ days after infection. C) An indirect immunoperoxidase technique was used to demonstrate a few parasitized macrophages among epithelioid cells in L. major-infected mice (arrowhead) (original magnification $\times 280) 42$ days after infection. D) Immunoperoxidase staining clearly shows many macrophages within large cytoplasmic parasitophorous vacuoles containing amastigote forms of $L$. amazonensis in the lesion of a CBA mouse (original magnification $\times 280) 42$ days after infection. E) At the end of the experiment (70 days) L. major-infected CBA mice showed a small focus of inflammatory infiltrate containing mononuclear cells and fibrosis (arrowheads). No parasitized cells were observed ( $\mathrm{H} \& \mathrm{E}$, original magnification $\times 140)$. F) At the end of the experiment L. amazonensisinfected mice showed an extensive collection of vacuolated and parasitized macrophages with focal areas of necrosis (N) and infiltration of granulocytes $(\mathrm{H} \& \mathrm{E}$, original magnification $\times 70) 70$ days after infection.

sitized macrophages increased progressively. Only a few lymphocytes were observed in the periphery of the lesions. Extensive areas of necrosis altered this monotonous picture. In these areas of necrosis free amastigote parasites were seen among inflammatory cells. Occasionally, areas of necrosis were infiltrated by granulocytes, giving rise to micro abscess (figure 4F). At 70 days post-infection, skin ulceration was observed. In this group of mice, granulomas were not seen at any time point.

Sections from the draining lymph nodes also showed clear differences between the two groups of infected mice. In resistant mice infected with $L$. major, macrophages with an epithelioid appearance formed small granulomas that were scattered in the parenchyma of the lymph nodes (figure 5A). Although parasites were not found or were scarce at the site of skin infection 70 days after inocula- tion, few intact amastigote forms were found in granulomas in the draining lymph nodes by that time (figure $5 B$ ).

In the $L$. amazonensis-infected mice, granulomas were not seen in the draining lymph nodes. The cortical sinus was distended by the presence of macrophages containing intact parasites and their antigens in their cytoplasm (figure $5 C, D)$. Progressively, many macrophages, heavily parasitized or containing parasite antigens (demonstrated by immunohistochemistry) and plasma cells replaced all the lymph node parenchyma (figure 5F).

Apoptosis of lymphocytes in the draining lymph nodes of $L$. amazonensis-infected mice was a distinctive feature. This type of cell death was attained by lymphocytes in the follicles and in the parafollicular areas of the lymph nodes. This phenomenon was less evident in L. major-infected mice (data not shown). 


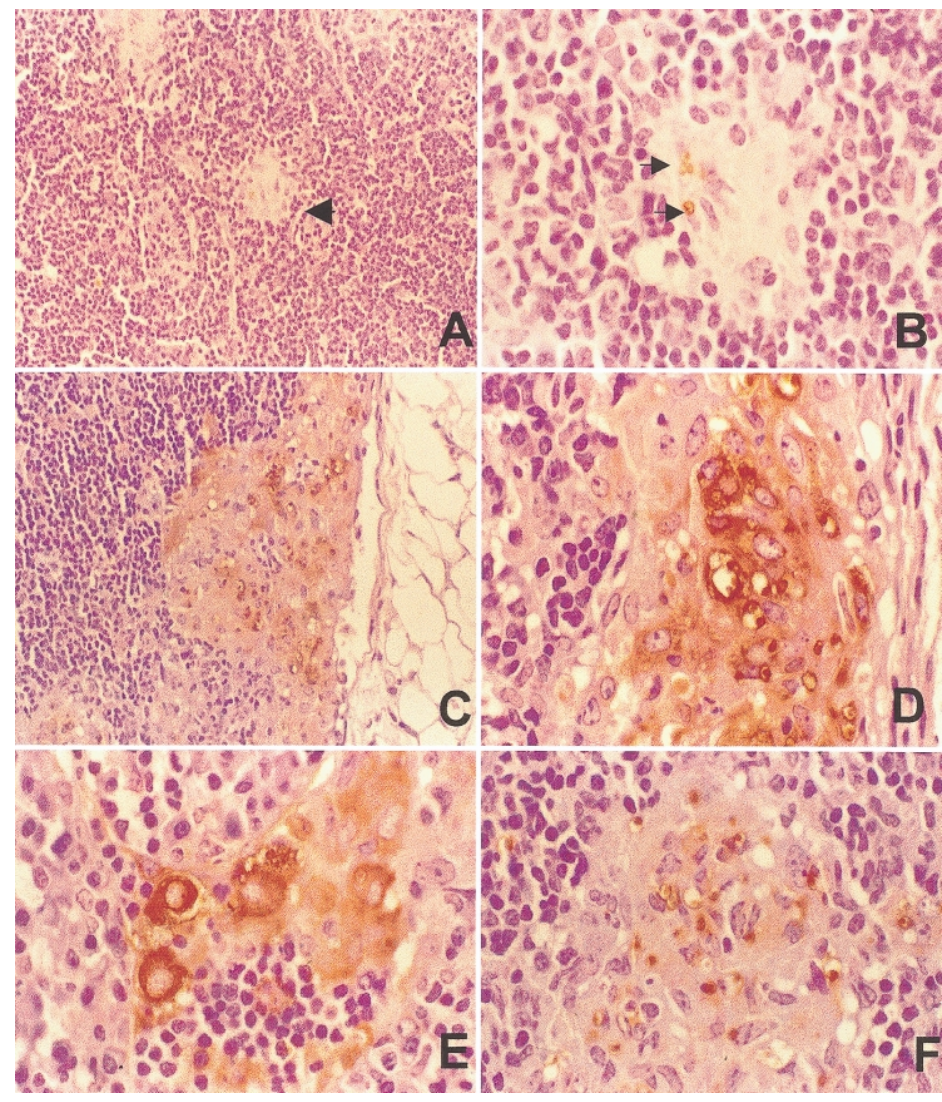

Figure 5. Histological changes in the draining lymph nodes. A) Popliteal lymph node draining a 70-day-old lesion in a CBA mouse infected with L. major. A small collection of epithelioid macrophages formed granulomas (arrow) (H \& E, original magnification $\times 140$ ). B) Immunoperoxidase staining was used to demonstrate a few well-preserved amastigote forms of $L$. major in the draining lymph node of a 70-day-old lesion in a CBA mouse (arrow). Parasites are seen inside a granuloma (original magnification $\times 280$ ). C) Popliteal lymph node draining a 14-day-old lesion in a CBA mouse infected with L. amazonensis. The cortical sinus is distended by macrophages that contain intact amastigote forms of the parasite and their antigens. An antibody against leishmania was used for immune-staining (original magnification $\times 140$ ) (immunoperoxidase staining using an antibody against leishmania, original magnification $\times 280)$. D) A detail from an area similar to that shown in C). Macrophages contain Leishmania antigens and intact parasites (original magnification $\times 280$ ). E) Lymph node draining a 70-day-old lesion in a CBA mouse infected with L. amazonensis. Sinuses were occupied by large cells containing Leishmania antigens and parasites. Plasma cells and lymphocytes are seen in the parenchyma (immunoperoxidase staining, original magnification $\times 280$ ). F) Large collection of parasitzed macrophages in the lymph node draining a 70-day-old lesion in a CBA mouse infected with L. amazonensis (immunoperoxidase staining, original magnification $\times 280$ ).

\section{Discussion}

Our results clearly show that in the same inbred strain of mice, different species of Leishmania determine totally distinct cellular immune responses and histopathological changes. Such futures are similar to those observed when one species of Leishmania is used to infect strains of mice that are known to be genetically susceptible or resistant to the infection or in previously immunized animals $[7,8,11$, $27,28]$. The data indicate that factors related to the parasite used to infect mice, in addition to those from the host, are determinant of the type of cellular immune response, and consequently of the outcome of the infection.

The approach used here avoids the problem of differences in the genetic background of the host and opens up the possibility of investigating factors related to the parasite that can influence the type of immune response.

Our data show that resistance of CBA mice to infection with L. major is related to a Th1-type cellular immune response, whereas susceptibility to $L$. amazonensis correlates with a Th2-type response. Moreover, morphological studies demonstrate that different tissue responses correlate with resistance and susceptibility [27]. It is possible that some factors in $L$. amazonensis inhibit the differentiation of Th1 cells. Transforming growth factor (TGF)- $\beta$ and IL-10 favor Th2-cell development, while IL-12 favors Th1 cells [29-31]. Preliminary results from our laboratory have shown that peritoneal macrophages from CBA mice infected with $L$. amazonensis produced considerably more IL-10 and TGF- $\beta$ than macrophages infected with L. major. The effect of L. amazonensis and L. major on the 
production of IL-12 by macrophages of CBA mice is currently under investigation.

In the initial phase of the infection of CBA mice with L. major a Th1/Th2 or Th0 type of immune response was observed. Cells from the draining lymph nodes of these mice produced IFN- $\gamma$, IL-4 and IL-10. Similar results were described by Reiner et al. [32] for the initial response of $\mathrm{C} 57 \mathrm{BL} / 6$ and $\mathrm{BALB} / \mathrm{c}$ mice infected with L. major.

Despite the presence of high amounts of IL-4 and IL-10 in the first week after the infection of CBA mice with L. major, it seems that the presence of IFN- $\gamma$ is enough to prevent the development of a Th2-type response and favor a typical Th1-type response. On the other hand, in CBA mice susceptible to $L$. amazonensis, cells from the draining lymph node did not produce significant amounts of IFN- $\gamma$, but high levels of IL-4 were detected from the beginning to the end of the study. The amounts of IL-4 and IL-10 in L. amazonensis-infected mice were less than those observed in L. major-infected mice in the first week; however, in the absence of IFN- $\gamma$, a commitment to a Th2-type immune response occurred.

C57BL/ 6 and C57BL/10 mice are susceptible to $L$. amazonensis $[17,19]$. However, the mechanism related to susceptibility in these strains of mice is different from that observed in CBA mice. C57BL/10 mice are unable to cure lesions induced by $L$. amazonensis infection. But unlike $\mathrm{CBA}$ mice, in $\mathrm{C} 57 \mathrm{BL} / 10$ mice the lesions are not progressive and parasite dissemination is not observed. IFN- $\gamma$ and IL-4 are detected at the beginning of the infection, but later on IL-4 is not produced [17]. Similar results are observed with C57BL/6 mice infected with L. amazonensis [19]. In both strains of C57BL mice susceptibility did not correlate with the levels of IL-4. In contrast, CBA mice, like susceptible BALB/C mice infected with $L$. amazonensis, produce high levels of IL-4 when infected with L. amazonensis, and parasite dissemination occurs. Taken together, these observations suggest that IL-4 may be important for parasite dissemination.

In the first week after infection, the production of IL-10 was higher in mice infected with L. major than in mice infected with $L$. amazonensis. Thereafter the levels of IL-10 decreased progressively in L. major-infected CBA mice, while in L. amazonensis-infected mice, IL-10 increased 49 days post-infection and decreased 70 days postinfection. Soares et al. [33] reported that CBA mice infected with L. major produced more IL-10 than did infected $\mathrm{BALB} / \mathrm{c}$ mice. They suggested that IL-10 is produced by CBA mice to prevent overproduction of IFN- $\gamma$ in response to infection with $L$. major. Our results reinforce the idea that the presence of IL-10 is not enough by itself to favor a Th2 response. Possibly, IL-10 has a dual role in the immune response to leishmania. In the context of susceptibility, it favors a Th2 response, whereas in the context of resistance, it down regulates the Th1 response and modulates the immune response.

NO production is considered to be important in the killing of L. major by infected macrophages [34]. In the present study, the fact that cells from susceptible CBA mice infected with $L$. amazonensis produced more NO than did cells from resistant mice infected with $L$. major was unexpected. Since NO was measured in the draining lymph node and the number of macrophages was much higher in L. amazonensis-infected mice than in L. major-infected ones, it is possible that NO was not detected in the latter because there were not enough cells to produce measurable amounts of NO. The reason why NO does not kill L. amazonensis is not known. Several hypotheses need to be tested: 1) the level of NO that is necessary to kill L. major is not enough to kill L. amazonensis; 2) factors that may act synergistically with $\mathrm{NO}$ in the killing of L. major, such as $\mathrm{O}_{2}$ metabolites, are lacking in L. amazonensis infection; 3$) L$. amazonensis directly neutralizes or inhibits the killing action of NO. In addition to controlling parasite infection, $\mathrm{NO}$ contributes to tissue destruction and inflammation [35]. Thus, it is possible that during infection with $L$. amazonensis high levels of $N O$, instead of controlling the infection, are actually making the lesions worse.

Morphological features in the lesions correlate with resistance or susceptibility in both humans and experimental cutaneous leishmaniasis $[27,28,36]$. In the present study we confirm and extend previous results. Mice with the same genetic background show distinct morphological features whether they are resistant or susceptible to different species of Leishmania. Additionally, we demonstrate that the histopathological response is also different in the draining lymph nodes in resistant and susceptible mice. Susceptible mice showed a diffuse infiltration of macrophages containing parasite antigens and intact parasites. Moreover, they showed extensive apoptosis and progressive replacement of the lymphocytes by plasma cells and parasitized macrophages. In resistant mice few granulomas containing intact forms of L. major were observed in the lymph node.

In the present study, avoiding the pitfalls of analysis in animals of diverse genetic background, we were able to show that the parasite is implicated in driving the immune response. Additionally, this model helped in the understanding of the roles of IL-4 and IL-10 in the initial stages of Leishmania infection. The knowledge of these factors may be useful in future strategies for the development of vaccines.

\section{Acknowledgments}

Supported by grant no. 522305/96.2 from the Brazilian Council for Scientific and Technological Development (CNPq), PRONEX and FIOCRUZ (PAPES - 0250.250.354). We are indebted to Dr Manoel Barral-Netto and Dr Washington Luis Conrado dos Santos for their suggestions during manuscript preparation.

\section{References}

[1] Lainson R., Shaw J.J., in: Peters W., Killick-Kendrick R. (Eds.), The Leishmaniases, Academic Press Inc., London, 1987, pp. 1-119.

[2] Grimaldi G.J., Tesh R.B., Leishmaniases of the New World: current concepts and implications for future research, Clin. Microbiol. Rev. 6 (1993) 230-250. 
[3] Cáceres-Dittmar G., Tapia F.J., Sánchez M.A., Yamamura M., Uyemura K., Modlin R.L., Bloom B.R., Convit J., Determination of the cytokine profile in American cutaneous leishmaniasis using the polymerase chain reaction, Clin. Exp. Immunol. 91 (1993) 500-505.

[4] Castes M., Agnelli A., Verde O., Rondón A.J., Characterization of the cellular immune response in American cutaneous leishmaniasis, Clin. Immunol. Immunopathol. 27 (1983) 176-186.

[5] Howard J.G., Hale C., Liew F.Y., Immunological regulation of experimental cutaneous leishmaniasis. III. Nature and significance of specific suppression of cell-mediated immunity in mice highly susceptible to Leishmania tropica, J. Exp. Med. 152 (1980) 594-607.

[6] Titus R.G., Milon G., Marchal G., Vassalli P., Cerottini J.C., Louis J.A., Involvement of specific Lyt-2+ T cells in the immunological control of experimentally induced murine cutaneous leishmaniasis, Eur. J. Immunol. 17 (1987) 1429-1433.

[7] Heinzel F.P., Sadick M.D., Mutha S.S., Locksley R.M., Production of interferon gamma, interleukin 2, interleukin 4 , and interleukin 10 by CD4 + lymphocytes in vivo during healing and progressive murine leishmaniasis, Proc. Natl. Acad. Sci. USA 88 (1991) 7011-7015.

[8] Locksley R.M., Heinzel F.P., Sadick M.D., Holaday B.J., Gardner K.D.J., Murine cutaneous leishmaniasis: susceptibility correlates with differential expansion of helper T-cell subsets, Ann. Inst. Pasteur Immunol. 138 (1987) 744-749.

[9] Scott P., Natovitz P., Coffman R.L., Pearce E., Sher A., Immunoregulation of cutaneous leishmaniasis. T cell lines that transfer protective immunity or exacerbation belong to different $\mathrm{T}$ helper subsets and respond to distinct parasite antigens, J. Exp. Med. 168 (1988) 1675-1684.

[10] Liew F.Y., Functional heterogeneity of CD4+ T cells in leishmaniasis, Immunol. Today 10 (1989) 40-45.

[11] Heinzel F.P., Sadick M.D., Holaday B.J., Coffman R.L., Locksley R.M., Reciprocal expression of interferon gamma or interleukin 4 during the resolution or progression of murine leishmaniasis. Evidence for expansion of distinct helper T cell subsets, J. Exp. Med. 169 (1989) 59-72.

[12] Neal R.A., Hale C., A comparative study of susceptibility of inbred and outbred mouse strains compared with hamsters to infection with New World cutaneous leishmaniasis, Parasitology 87 (Pt 1) (1983) 7-13.

[13] Childs G.E., Lightner L.K., McKinney L., Groves M.G., Price E.E., Hendricks L.D., Inbred mice as model hosts for cutaneous leishmaniasis. I. Resistance and susceptibility to infection with Leishmania braziliensis, L. mexicana, and $L$. aethiopica, Ann. Trop. Med. Parasitol. 78 (1984) 25-34.

[14] Barral-Netto M., Barral A., Brownell C.E., Skeiky Y.A., Ellingsworth L.R., Twardzik D.R., Reed S.G., Transforming growth factor-beta in leishmanial infection: a parasite escape mechanism, Science 257 (1992) 545-548.

[15] DeKrey G.K., Lima H.C., Titus R.G., Analysis of the immune responses of mice to infection with Leishmania braziliensis, Infect. Immun. 66 (1998) 827-829.

[16] Alexander J., A radioattenuated Leishmania major vaccine markedly increases the resistance of CBA mice to subsequent infection with Leishmania mexicana mexicana, Trans. R. Soc. Trop. Med. Hyg. 76 (1982) 646-649.
[17] Afonso L.C., Scott P., Immune responses associated with susceptibility of C57BL/10 mice to Leishmania amazonensis, Infect. Immun. 61 (1993) 2952-2959.

[18] Calabrese K da S., da Costa S.C., Enhancement of Leishmania amazonensis infection in BCG non-responder mice by BCG-antigen specific vaccine, Mem. Inst. Oswaldo Cruz 87 (Suppl. 1) (1992) 49-56.

[19] Soong L., Chang C.H., Sun J., Longley B.J.J., Ruddle N.H., Flavell R.A., McMahon-Pratt D., Role of CD4+ $\mathrm{T}$ cells in pathogenesis associated with Leishmania amazonensis infection, J. Immunol. 158 (1997) 5374-5383.

[20] Behin R., Mauel J., Sordat B., Leishmania tropica: pathogenicity and in vitro macrophage function in strains of inbred mice, Exp. Parasitol. 48 (1979) 81-91.

[21] Champsi J., McMahon-Pratt D., Membrane glycoprotein M-2 protects against Leishmania amazonensis infection, Infect. Immun. 56 (1988) 3272-3279.

[22] Sadigursky M., Brodskyn C.I., A new liquid medium without blood and serum for culture of hemoflagellates, Am. J. Trop. Med. Hyg. 35 (1986) 942-944.

[23] Soares N.M., Carvalho E.M., Pinho R.T., Pontes de Carvalho L.C., Induction of complement-sensitivity in Leishmania amazonensis metacyclic promastigotes by protease treatment but not by specific antibodies, Parasitol. Res. 79 (1993) 340-342.

[24] Curry R.C., Kiener P.A., Spitalny G.L., A sensitive immunochemical assay for biologically active MuIFN-gamma, J. Immunol. Methods 104 (1987) 137-142.

[25] Ding A.H., Nathan C.F., Stuehr D.J., Release of reactive nitrogen intermediates and reactive oxygen intermediates from mouse peritoneal macrophages. Comparison of activating cytokines and evidence for independent production, J. Immunol. 141 (1988) 2407-2412.

[26] Moore K.W., Vieira P., Fiorentino D.F., Trounstine M.L., Khan T.A., Mosmann T.R., Homology of cytokine synthesis inhibitory factor (IL-10) to the Epstein-Barr virus gene BCRFI, Science 248 (1990) 1230-1234.

[27] Andrade Z.A., Reed S.G., Roters S.B., Sadigursky M., Immunopathology of experimental cutaneous leishmaniasis, Am. J. Pathol. 114 (1984) 137-148.

[28] Barral-Netto M., de Freitas L.A., Andrade Z.A., Histopathologic changes induced by vaccination in experimental cutaneous leishmaniasis of BALB/c mice, Am. J. Pathol. 127 (1987) 271-278.

[29] Scharton-Kersten T., Afonso L.C., Wysocka M., Trinchieri G., Scott P., IL-12 is required for natural killer cell activation and subsequent $\mathrm{T}$ helper 1 cell development in experimental leishmaniasis, J. Immunol. 154 (1995) 5320-5330.

[30] Sypek J.P., Chung C.L., Mayor S.E., Subramanyam J.M., Goldman S.J., Sieburth D.S., Wolf S.F., Schaub R.G., Resolution of cutaneous leishmaniasis: interleukin 12 initiates a protective T helper type 1 immune response, J. Exp. Med. 177 (1993) 1797-1802.

[31] Schmitt E., Hoehn P., Huels C., Goedert S., Palm N., Rüde E., Germann T., T helper type 1 development of naive CD4+ $\mathrm{T}$ cells requires the coordinate action of interleukin-12 and interferon-gamma and is inhibited by transforming growth factor-beta, Eur. J. Immunol. 24 (1994) 793-798. 
[32] Reiner S.L., Zheng S., Wang Z.E., Stowring L., Locksley R.M., Leishmania promastigotes evade interleukin 12 (IL-12) induction by macrophages and stimulate a broad range of cytokines from $\mathrm{CD} 4+\mathrm{T}$ cells during initiation of infection, J. Exp. Med. 179 (1994) 447-456.

[33] Soares M.B., David J.R., Titus R.G., An in vitro model for infection with Leishmania major that mimics the immune response in mice, Infect. Immun. 65 (1997) 2837-2845.

[34] Liew F.Y., Li Y., Moss D., Parkinson C., Rogers M.V., Moncada S., Resistance to Leishmania major infection correlates with the induction of nitric oxide synthase in murine macrophages, Eur. J. Immunol. 21 (1991) 3009-3014.
[35] Giorgio S., Linares E., Ischiropoulos H., Von Zuben F.J., Yamada A., Augusto O., In vivo formation of electron paramagnetic resonance-detectable nitric oxide and of nitrotyrosine is not impaired during murine leishmaniasis, Infect. Immun. 66 (1998) 807-814.

[36] Ridley D.S., Ridley M.J., The evolution of the lesion in cutaneous leishmaniasis, J. Pathol. 141 (1983) 83-96. 